\title{
WPA guidance on mental health and mental health care in migrants
}

\author{
Dinesh Bhugra ${ }^{1}$, Susham Gupta ${ }^{2}$, Kamaldeep Bhul ${ }^{3}$, Tom Craig ${ }^{1}$, Nisha Dogra ${ }^{4}$, \\ J. David Ingleby ${ }^{5}$, James Kirkbride ${ }^{6}$, Driss Moussaoui ${ }^{7}$, James Nazroo ${ }^{8}$, Adil Qureshi ${ }^{9}$, \\ Thomas Stompe ${ }^{10}$, Rachel Tribe ${ }^{11}$
}

${ }^{1}$ Institute of Psychiatry, King's College London, De Crespigny Park, London SE5 8AF, UK; ${ }^{2}$ East London NHS Foundation Trust, London, UK; ${ }^{3}$ Queen Mary School
of Medicine and Dentistry, London, UK; ${ }^{4}$ Greenwood Institute of Child Health, University of Leicester, UK; ${ }^{5}$ European Research Centre on Migration and Ethnic
Relations, University of Utrecht, The Netherlands; 6 University Department of Psychiatry, Addenbrooke's Hospital, Cambridge, UK; ${ }^{7}$ Ibn Rushd University Psychiatric
Centre, Casablanca, Morocco; ${ }^{8}$ University of Manchester, UK; ${ }^{9}$ Vall d'Hebron University Hospital, Barcelona, Spain; ${ }^{10}$ Psychiatric University Clinic, Vienna, Austria;
${ }^{11}$ School of Psychology, University of East London, London, UK

The purpose of this guidance is to review currently available evidence on mental health problems in migrants and to present advice to clinicians and policy makers on how to provide migrants with appropriate and accessible mental health services. The three phases of the process of migration and the relevant implications for mental health are outlined, as well as the specific problems of groups such as women, children and adolescents, the elderly, refugees and asylum seekers, and lesbian, gay, bisexual and transgender individuals. The concepts of cultural bereavement, cultural identity and cultural congruity are discussed. The epidemiology of mental disorders in migrants is described. A series of recommendations to policy makers, service providers and clinicians aimed to improve mental health care in migrants are provided, covering the special needs of migrants concerning pharmacotherapies and psychotherapies.

Key words: Migrants, mental health, cultural bereavement, cultural identity, cultural congruity, schizophrenia, common mental disorders, suicide, pharmacotherapies, psychotherapies, mental health services

(World Psychiatry 2011;10:2-10)

The WPA is committed to promote equity in the access to mental health services for persons of different age, gender, race/ethnicity, religion and socioeconomic status. As part of this commitment, the Association decided to devote one of the guidances to be developed within its Action Plan 2008-2011 $(1,2)$ to mental health and mental health care in migrants. A Task Force was appointed for this purpose, which produced the present document.

Mental health practitioners work in an increasingly multicultural world, shaped by the migrations of people of many different cultural, racial and ethnic backgrounds. People migrate for many reasons: political, socioeconomic and educational. The diversity of cultures, ethnicity, races and reasons for migration can make understanding experiences of illness challenging in migrants whose background differs significantly from the clinician.

Culture has an important role in the presentation of distress and illness, and cultural differences impact upon the diagnosis and treatment of migrant populations in part due to linguistic, religious and social variation from the clinician providing care. Additionally, it appears that the incidence and prevalence of mental disorders varies among people of different cultural backgrounds, due to an interplay of biological, psychological and social factors. The provision of health care is necessarily influenced by the demands of people of many different cultures, and it is important that cultural differences be appreciated and understood to arrive at a correct diagnostic impression and treatment plan.

\section{MIGRATION AND MENTAL HEALTH IN MIGRANTS}

Migration is defined as the process of going from one country, region or place of residence to settle in another. The duration of this new settlement varies, but for the purposes of this report the focus is on individuals who relocate either semi-permanently or permanently to another country. Migrants may move en masse or singly. For example, people who migrate for economic or educational reasons may move singly and at a later date be joined by their families, whereas people who migrate due to political reasons may move en masse but with or without their families (3). A significant proportion of people who migrate will become an ethnic minority in the new country.

The process of migration has been described as occurring in broadly three stages. The first stage is pre-migration, involving the decision and preparation to move. The second stage, migration, is the physical relocation of individuals from one location to another. The third stage, post-migration, is defined as the "absorption of the immigrant within the social and cultural framework of the new society". Social and cultural rules and new roles may be learnt at this stage $(4,5)$. The initial stage of migration may have comparatively lower rates of mental illness and health problems than the latter stages, due to the younger age at that stage, and the problems with acculturation and the potential discrepancy between attainment of goals and actual achievement in the latter stages (6). It is worth noting that the stages are often not discrete and merge into one another.

During the stages of migration, there may be factors that 
predispose individuals to mental disorders. Pre-migration factors include the personality structure of an individual, forced migration, and persecution, among others. Migration factors include cultural bereavement. Culture shock, a discrepancy between expectations and achievement, and acceptance by the new nation are potential post-migration factors $(7,8)$. Table 1 provides a guide to the assessment of the above factors in migrants.

\section{Special groups}

Some groups have additional factors that need to be taken into account in assessment and management.

\section{Women}

Women may be the primary migrant or they may follow the primary migrant. Their experiences of migration and response to the stress will be different from those of men. Furthermore, changes in gender role after migration and gender role expectations will influence the way women respond to the stress of migration and post-migration adjustment. Increasing changes in demographics towards more women migrating and working full time mean that stress on women is increasing further.

\section{Children and adolescents}

Children and adolescents may have different reasons to migrate and may accompany the family or migrate by themselves, especially as refugees or asylum seekers. Separation from one or both parents, as part of or as a sequel of migration, may create problems in attachment and subsequent development. Seasonal regular migration of parents or serial migration of family members and other patterns of migration will create additional stress. Children may have difficulty in adjusting both at home and in school, and older children may end up looking after the younger ones.

\section{Elderly}

The reasons for migration of older adults may differ in comparison with younger ones. Elderly people may have migrated at an earlier stage of their career and life and may already feel settled down in the new country, or may migrate at an older age to the new country in order to join their family. Multiple jeopardy of ageing migrants related to racism, ageism, gender, poor access to services may all act as barriers to help seeking and health (9). Dementia, depression and anxiety among the elderly may vary according to the migrant status, but help seeking may vary as well $(9,10)$.
Table 1 Items to be covered in history taking with migrants

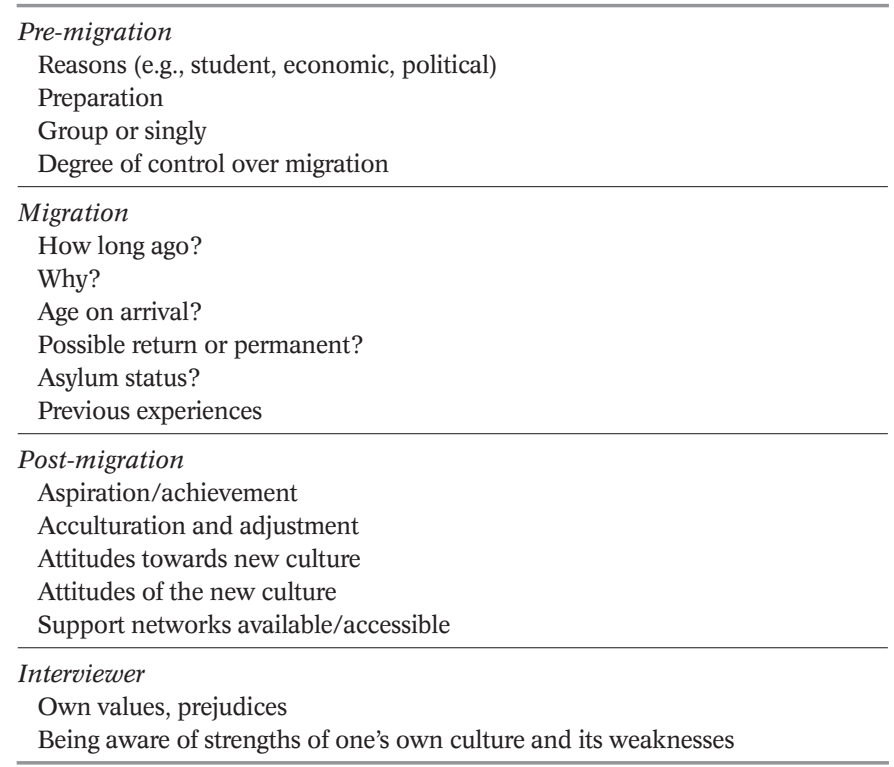

\section{Refugees and asylum seekers}

According to the Geneva Convention, a refugee is someone who has a "well-founded fear of being persecuted for reasons of race, religion, nationality, membership of a particular social group or political opinion, is outside the country of his nationality and is unable or owing to such fear is unwilling to avail himself of the protection of that country". An asylum seeker is someone who has left his/her country of origin, has applied to be recognized as a refugee and is awaiting a decision from the new government.

Refugees are perhaps the most vulnerable of all migrant groups to mental and physical ill health. Lack of preparation, attitudes of the new country, poor living conditions, poor or lack of employment and variable social support all add to this vulnerability. Rates of mental disorders may be high in some refugee groups: those of common mental disorders are twice as high in refugee populations in comparison with economic migrants (11).

The risk of post-traumatic stress disorder and common mental disorders increases with the length of stay in detention $(12,13)$ and is also related to unemployment, lack of family support and the complicated asylum process (11). Asylum seekers are less likely to engage with mental health services $(14,15)$. Pathologization and medicalization of common experiences must be avoided.

\section{Lesbian, gay, bisexual and transgender individuals}

Lesbian, gay, bisexual and transgender individuals (LGBT) may wish to escape if their country of origin holds these behaviours to be illegal. They may have problems 
coming out to themselves and to others, adding to internalized stress. They may choose to escape but the laws in the new countries may not allow this or prevalent public attitudes to LGBT may colour the societal responses. For transgender individuals, it may be a search for surgical/ medical interventions which drives them. Attitudes of the family, the ego-dystonia in the individual and homophobia in the new society will affect settling down.

\section{Cultural bereavement}

The loss of one's social structure and culture can cause a grief reaction (16). Migration involves the loss of the familiar, including language (especially colloquial and dialect), attitudes, values, social structures and support networks. Grieving for this loss can be viewed as a healthy reaction and a natural consequence of migration; however, if the symptoms cause significant distress or impairment and last for a significant period of time, psychiatric intervention may be warranted. Eisenbruch (17) has defined cultural bereavement as an experience resulting from loss of social structures, cultural values and selfidentity. The person lives in the past, is visited by supernatural forces from the past while asleep or awake, and experiences feelings of guilt. Images of the past (including traumatic images) intrude into his/her life, and he/she is struck by anxieties, morbid thoughts, and anger. The symptoms of cultural bereavement may be misdiagnosed due to problems with language and culture, and the use of Western diagnostic criteria in non-Western people.

\section{Cultural identity}

Psychosocial changes experienced by immigrants include acculturation, a process that may be voluntary or forced, which results in the assimilation of cultural values, customs, beliefs and language of the majority community (18). Changes in attitudes, family values, generational status and social affiliations can occur in both the majority and minority cultures as the two interact; however, typically one culture tends to dominate (19).

Cultural changes in identity can be stressful and result in problems with self-esteem and mental health. Contact between the immigrant, or minority, community with the dominant, or new community may lead to assimilation, rejection, integration or deculturation (4). Rejection, in which the individual or minority group withdraws from the majority group, can lead to apartheid or segregation in extreme cases. Deculturation, in which the individual or minority group experiences a loss of cultural identity, alienation and acculturative stress, can lead to ethnocide (4). Post-migration stresses include culture shock and conflict, both of which may lead to a sense of cultural confusion, feelings of alienation and isolation, and depression
(7). New societies' attitudes, including racism, compounded by stresses of potential unemployment, a discrepancy between achievement and expectations, financial hardships, legal concerns, poor housing and a general lack of opportunities for advancement within the host society, can lead to mental health problems in vulnerable individuals.

Acculturation may enable culturally bereaved individuals to gain a semblance of equilibrium. Migrants who experience the loss of their culture and guilt over leaving their homeland may find that, as acculturation proceeds, a sense of belonging in the new country occurs. The majority culture may seem less threatening and more inviting as the individual becomes more linguistically and socially proficient in this new culture. Social support can ensue in the forms of friendships, employment opportunities, and medical care. Integration and assimilation can help reduce feelings of loss and grief as the migrant starts to incorporate aspects of the majority culture.

In acculturation, the interaction of the migrant's culture with the majority culture of the new country is a dynamic and reciprocal process that can result in changes in the broader cultural group, enhancing the ability of people of the dominant culture to better appreciate and understand aspects of the immigrant's culture and recognize some of the needs of those who have migrated.

\section{Cultural congruity}

Ethnic density, i.e. the size of a particular ethnic group in proportion to the total population in a specified area, may be a factor that influences the rates of mental disorders in ethnic minorities. Additionally, a sense of alienation may occur if the cultural and social characteristics of an individual differ from those of the surrounding population, whereas a sense of belonging tends to occur if the individual and surrounding population have similar cultural and social characteristics.

An increase in ethnic density may improve the social support and the adjustment of some individuals who have migrated, yet increase distress in others, in particular if there exists a cultural conflict between the individual and his/her culture of origin (8). This may account for some of the conflicting results from studies of the relationship between ethnic density and the incidence of mental illness in ethnic minority groups. For example, an inverse correlation between the incidence of schizophrenia in non-White ethnic minorities in London and the proportion of those minorities in the local population was found; it was hypothesized that increased exposure to or a lack of protection from stress may increase the rate of schizophrenia in non-White ethnic minorities (20); however, a previous study failed to support the ethnic density hypothesis for the increased incidence of schizophrenia in immigrant groups (21).

It is important to consider the nature of the society an individual has migrated from and to, and the social char- 
acteristics of the individual who has migrated, in determining how well a person will adjust during the migration process. Sociocentric or collectivist societies stress cohesiveness, strong ties between individuals, group solidarity, emotional inter-dependence, traditionalism and a collective identity. Egocentric or individualistic societies stress independence, loose ties between individuals, emotional independence, liberalism, self-sufficiency, individual initiative, and autonomy. Bhugra (22) has hypothesized that individuals who migrate from predominately sociocentric, or collectivist, societies into a society that is predominately egocentric, or individualistic, are likely to have problems adjusting to the new culture, especially if the individuals are sociocentric in their own belief system. A consequent lack of an adequate social support system, a disparity between expectations and achievements and a low self-esteem may result from this dissonance in culture between the individual and the surrounding population.

An increase in ethnic density may help decrease the distress of the individual in this situation, especially by providing a social support system. For example, a person who migrates to the United States, a predominately egocentric society, from Vietnam, a predominately sociocentric society, may feel isolated and alienated, especially if the individual is sociocentric in outlook. Feelings of isolation and alienation may be decreased, and social support improved, if other people from Vietnam, with sociocentric views, surround this person in the area of resettlement; however, the sociocentric individual may remain on the periphery of the new country's society since linguistic and social fluency of the dominant culture may not be attained.

Cultural bereavement may also be minimized if the immigrant is able to maintain ties to the culture of origin, either through increased ethnic density, improved social support or maintenance of religious beliefs and practise. Individuals who migrate from a predominately sociocentric culture into a society that is predominately egocentric in nature may experience little in the way of problems, and a relatively easy transition to the new culture, if they are mostly egocentric, or individualistic, in their outlook. In this case, an increase in ethnic density may be disadvantageous and exacerbate or cause cultural conflict and mental distress.

\section{EPIDEMIOLOGY OF MENTAL DISORDERS IN MIGRANTS}

\section{Schizophrenia}

Ödegaard (23) first reported that the rates of schizophrenia among Norwegians who had migrated to the USA were higher when compared with Norwegians in Norway. He noted that the peak of admission rates occurred 10-12 years after migration and saw this as a result of migration.

Subsequently, several studies have shown that migrants, especially African-Caribbeans in the UK and in the Netherlands, have rates of schizophrenia between 2.3 and 16 times those of local White populations $(24,25)$. A threefold risk for schizophrenia in migrants has been reported in a recent systematic review (26).

Cochrane and Bal (27) demonstrated that admission rates of patients with schizophrenia were elevated among the Irish, Pakistani, Caribbean and Indian born migrants. They put forward (28) various hypotheses to explain these differentials, which are considered briefly below.

The first hypothesis was that sending countries have high rates of schizophrenia. However, four studies from the Caribbean (29-32) reported no increase. Rates of schizophrenia in the UK have been shown to be higher among the younger (second) generation African-Caribbeans, indicating that genetic factors may not play a role and other social and environmental factors may be important $(33,34)$.

A second hypothesis was that schizophrenia predisposes to migration. The individual with schizophrenia feels restless and this contributes to potential movement across boundaries. However, not only are there few data to support this, but, if that were the case, rates would be high in every migrant group, which is not what is reported.

A third hypothesis was that migration produces stress. Migration and related losses are significant life events and may contribute to the genesis of schizophrenia. However, as Ödegaard (23) demonstrated, the peak of the rates is 10-12 years post migration. Separation from parents has been shown to be more common in African-Caribbeans in comparison with South Asians and also in comparison with community controls (35), which may suggest that insecure attachment patterns may contribute to a disjointed sense of the self, thereby affecting cultural identity.

A fourth hypothesis was that a misdiagnosis of schizophrenia was involved, due to a lack of awareness of migrants' culture and norms (36,37). Bhugra et al (38) showed that, in their Trinidad sample, delusions of persecution were rare, but visual hallucinations commoner than the London group. Stompe et al (39) also noted cultural differences in symptoms.

Ethnic density has been shown to be an important factor in understanding the elevated rates of schizophrenia in some migrant groups $(20,40)$. Bhugra $(22)$ postulated that cultural congruity, when people with similar cultural values live close to one another, may be more important in this respect. Further work is urgently needed to map cultural congruity and ethnic density with epidemiological data.

Parker and Kleiner (41) hypothesized that a discrepancy between achievement and expectation may have contributed to high rates of psychoses in their sample. This has been replicated in London, especially for discrepancy between aspirations and achievements in housing (42,43), which may affect an individual's self-esteem. Why this lack of self-esteem should lead to schizophrenia and not depression needs to be explored further. Racial harassment 
is not uncommon and may further contribute to low selfesteem (44). Veling et al (45) found perceived discrimination to match the rates of psychosis in migrants.

\section{Common mental disorders}

There have been a number of population studies in the UK which have looked at the rates of common mental disorders in migrants. The findings have not been entirely consistent. It is not surprising that immediately after migration individuals may be optimistic and hopeful, and thus show low levels of depression and anxiety, which may change as they start to settle down, feel let down by the new culture and perhaps their own culture and start to ruminate over losses they have faced, thereby leading to depression. Some studies show that the rates of common mental disorders among migrants are higher than among the members of the new culture, but others show either no difference or lower rates (46-48).

The EMPIRIC study in the UK reported that Pakistani women were 1.37 times more likely and Bangladeshi women were 0.65 times less likely to have common mental disorders (48). From the same data set, Weich et al (47) noted that older women of Indian and Pakistani origin (aged 55-74) had higher rates of common mental disorders. This may reflect the period since migration and deserves to be studied further. One possibility is that the migrant feels trapped and develops a sense of defeat which may lead to depression. Gilbert and Allan (49) associated entrapment in an area with learned helplessness. Nazroo (46) reported that those who migrated before the age of 11 or who were born in Britain were much more likely (2.5 times for the Caribbean and Indian group, and 1.5 times in the Bangladeshi and Pakistani samples) to receive a diagnosis of an anxiety disorder. Those who were fluent in English were especially more likely to be diagnosed with an anxiety disorder.

\section{Post-traumatic stress disorder}

Political refugees or those escaping war or natural disasters will respond differently to trauma (50). Jenkins (51) noted that Salvadoran refugee women in North America explained their suffering as "nervios" - a cultural category including dysphoria, aches and pains and subjective bouts of feeling intense heat which are a culturally created normative response to abnormal stressors. Similar experiences have been described among Tibetan (52) and Khmer refugees (53).

\section{Suicide and attempted suicide}

The rates of attempted and completed suicide have been shown to be elevated in the South Asian female diaspora around the globe (54). The rates are raised among younger women aged 18-25, but not among adolescents $(55,56)$. This increase around the age 18 suggests that, when women start to individuate and find their way in the world, an element of culture conflict with their parents or family members may play a role. Comparing cultural identity between the adolescents and their parents, it was found that adolescents who took overdoses held less traditional views compared with their parents. McKenzie et al (57) noted that rates of suicide were higher than expected among older Asian females.

Rates of suicide among British, New Zealander and Irish migrants to Australia were higher compared with the rates in their countries of origin (58). Low rates among South Europeans were explained as a result of pre-migration health checks. Morrell et al (59) also reported from Australia that rates among North Europeans were higher, while Middle Eastern women showed very low rates. Socio-economic status for men (60), cultural transitions and tensions for women (61) and quality of life and emotional functioning (62) are some of the factors influencing rates of suicide.

\section{MENTAL HEALTH CARE IN MIGRANTS}

Table 2 lists a series of recommendations to policy makers, service providers and clinicians aimed to improve mental health care in migrants. Some more specific issues are highlighted in the following sections.

\section{Physical health}

The physical health of migrants needs to be explored in every assessment for a number of reasons. Mental disorders may be hiding underlying infectious diseases, which may influence their presentation. Physical conditions may be affected by psychiatric conditions. Individuals from traditional countries may not believe in mind-body dualism and may present with somatic symptoms which may become medically unexplained, therefore leading to unnecessary, often obtrusive, investigations adding to stress. The clinician must carry out a full physical examination and necessary investigations as indicated, providing a clear explanation for what is done.

\section{Pharmacological treatments}

Due to different pharmacokinetics and pharmacodynamics of psychotropic drugs, a number of ethnic groups show an increased vulnerability to side effects. With a fixed dose regimen of haloperidol, Asians experienced significantly more extrapyramidal side effects than Whites 
Table 2 Recommendations to improve mental health care in migrants

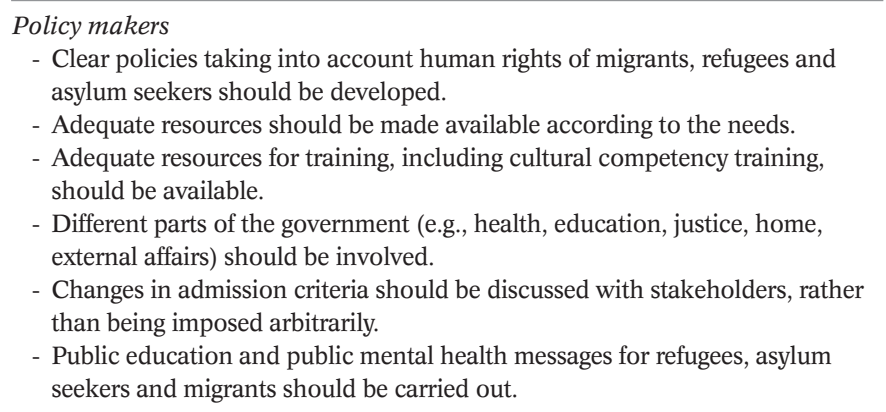

Service providers

Separate or joined up services should be made available, but it is essential that there are no barriers to help seeking.

Services should be culturally sensitive, geographically accessible and emotionally appropriate.

Cultural competence training must be provided and mandatory measures to achieve this should be considered.

Other models, such as culture broker or cultural liaison, should be employed where indicated.

Regular research into epidemiological factors, along with qualitative approaches, should be carried out in order to assess and monitor pathology.

Regular audits into treatment accessibility, acceptability and usage must be conducted.

\section{Clinicians}

Clinicians must have access to resources informing them of specific cultural issues.

- Cultural awareness and competence training must be mandated and regular updates must form a part of this.

Clinicians must provide culturally appropriate services related to language and other needs of migrants, refugees and asylum seekers. Children, the elderly and other special groups must have their needs met.

- Clinicians may wish to discuss and develop specific services, either condition based (e.g., trauma) or gender based.

- Wherever possible, mental health issues of migrants, refugees and asylum seekers should be part of the curriculum and training of clinicians

- Cultural training is everyone's business and must be a part of training other health professionals, including primary care professionals.

(63). Hispanics are reported to require half the dose of a tricyclic antidepressant to achieve therapeutic benefit and are more sensitive to side effects (64). African Americans are said to be at greater risk of developing lithium toxicity, because the lithium-sodium counter-transport pathway, a genetically determined mechanism that exchanges intracellular lithium for extracellular sodium, is less effective (65). Thus, clinicians must look out for differences in migrants and ensure that patients are started at low doses and then are gradually built up.

Different cultures have different attitudes and expectations of medication. Individuals may see herbal medication as more natural and acceptable. Those ethnic groups with a strong tradition of herbal remedies may hold beliefs antithetical to the advanced practice of psychopharmacology. The patients may engage in home preparation of the herbs, dosages are fixed, rapid relief is anticipated, side effects minimal, and switching to a new regimen is straightforward (66). If a medication fails to meet these ideals, it will be discontinued and the corresponding illness model disparaged.

Cultural attitudes also affect the interpretation of side effects, which may fit into the explanatory models held by the patient. For instance, the side effect profile of lithium is thought to be universal, but certain effects convey a culturally salient meaning (67). Chinese patients on long-term lithium are unperturbed by polydipsia and polyuria, because these are compatible with the perception that excess removal of toxins from the body is good, but do not welcome fatigue, as it may signify loss of vital energy (67).

Adherence is greatly influenced by the quality of the doctor-patient relationship. The view of the physician as an expert in collaboratively managing chronic conditions, currently favoured by professional bodies and patient groups in the West, might not conform to the "good" doctor in other cultures, where a more authoritative/directive style is preferred. When the patient's and the doctor's cultural groups have been in conflict, this may be played out in the consultation room, leading to a cultural transference and counter-transference which will affect adherence (68). Indeed, the reduced compliance with psychiatric treatment found in African Americans is said to be a result of this factor (69).

Cultural dietary practices will also directly impact upon the pharmacokinetics of a drug. CYP3A4 is inhibited by grapefruit juice and CYP1A2 by caffeine, and the latter is induced by cruciferous vegetables (cabbage, broccoli and brussels sprouts) and smoking. The induction of CYP1A2 by polycyclic aromatic hydrocarbons $(\mathrm{PAH})$ found in cigarette smoke leads to a fall in plasma levels of antidepressants and antipsychotics (70). Smoking is affected by religious values, thus rates vary significantly across ethnic groups. Grilling meat over a dry heat also produces $\mathrm{PAH}$, so CYP1A2 induction will occur in places where this is common, such as Turkey and many Asian countries.

Use of complementary medicines, often not declared to the doctor, either because it is seen as insignificant or because it is felt that doctors will not understand it, may cause pharmacological interactions. St. John's Wort and liquorice (commonly used in traditional Chinese medicine) increase the plasma levels of active metabolites of tricyclics, and may produce serious side effects (71). Other traditional medicines may contain large quantities of heavy metals - such as gold, silver, tin, copper, barium, lead, mercury, zinc, antimony and iron - that can cause toxicity. Associated prescriptions of changes in diet and fluid intake will influence absorption and action of medicines. Religious rituals such as fasting totally or partially can similarly alter the efficacy and tolerability of a prescribed drug.

Doctors must explore attitudes about the medication, expectations of its actions, religious beliefs, diet and use of tobacco and alcohol. It is always worth starting at a low dose, gradually building it up, monitoring side effects and 
keeping the patient and his/her carers as informed as possible.

\section{Psychotherapies}

Migrants face particular challenges when seeking assistance from psychotherapy services, not least their belief that such services may not apply to them, or be useful for them.

An accurate understanding of a person's cultural background is an essential prerequisite to effecting a helpful therapeutic relationship. For psychological treatments to work, especially in interpretive psychotherapy, the underlying philosophical basis of the approach must be acceptable to the patient. The therapist must allow the therapeutic technique to be modulated by the belief systems of the patients (and their families or carers who may have significant effect on the patient) rather than the other way around. Perhaps the most useful approach may be to tailor the therapy with the most relevant components of Western psychotherapy and the patient's own belief systems to effect the most useful therapeutic encounter.

Migrants may bring with them to the clinic their experience of racism, trauma, war, economic hardship, or enforced relocation. This must be listened to and taken seriously. Rathod et al (72) refer to work done with AfricanCaribbean patients in which it was necessary to allow the discussion of issues of slavery, racism, and discrimination raised during cognitive behavioural therapy to allow progress to occur.

Inevitably, the degree of acculturation of a patient will make a difference in them accepting therapy. It is possible that especially older Asian patients may see the professionals as authority figures, and expect a directive therapeutic encounter where they are told rather than collaborated with. A didactic style in the early stages may helping engaging the patient. The therapist must be aware of the cognitive styles within the patients' primary culture. Concepts of shame may be stronger in some cultures compared with notions of guilt, thus tailoring of therapy is important.

It can be argued that in sociocentric cultures it should be possible to use group psychotherapy, but this may also raise issues of confidentiality and cultural values adding to stigma. Different levels of linguistic competency and acculturation will add to difficulties. An ethnically diverse group may produce some splitting according to ethnic and racial factions with racial stereotypes playing a role. Members may feel that they are "representing" their culture, which may produce additional stress. Whether a multicultural group is more therapeutic compared with a homogeneous monocultural group depends upon the context and the purpose of the group.

Despite these potential difficulties, evidence suggests that group psychotherapy can be effective in assisting migrants with mental distress. Jenkins (51) states that "inter- racial and/or interethnic group therapy can be effective if the minority members satisfy themselves that the therapist is sensitive to their socio-cultural and personal situation". Hence, in a group setting with an ethnically diverse population, the responsibility lies with the therapist in ensuring that the difficulties do not inhibit the success of group therapy.

Like other patients, migrants approaching psychotherapy for the first time may carry a mental picture of their therapist and what to expect from him/her. This fantasy will be culturally moulded, influencing expectations and rapport. Patients from a traditional background in Eastern culture may perceive the role of the therapist to be analogous to the role of the guru or "spiritual teacher", who divines and explains in a directive manner. Similarly, in traditional African culture - specifically in some parts of Nigeria - Bhugra and Tantam (73) state that "the belief prevails that the most powerful healers know what the person's problem is before the person says anything. Taking a history is, according to this view, a symptom of therapeutic weakness".

The therapist's experience in general, and in working with ethnic minorities in particular, will affect therapeutic engagement. The therapist, by virtue of his/her position, may identify with the new culture to a greater extent than his/her patients, thus contributing to patients' alienation.

In couple therapy, mixed-race or intercultural couples will face specific issues of their own, especially related to acceptance by their family or kinship, which may cause additional stress. This may be used as an advantage in that in some cases they are together despite family opposition, which is an indication of the relationship's robustness. Gender role expectations in the new culture may change and cause stress. Obviously, therapists must explore whether the couple is experiencing distress due to cultural difference between the two partners or any other factors.

Refugees and asylum seekers may see the therapist as an authority figure who in their view can enable them to stay in the country, and help them receive social support and other non-medical outcomes. Thus, the therapist should make the purpose of the therapeutic encounter clear and also set realistic expectations about achievements and outcomes. Therapy may be terminated with little warning if the patient's asylum application is unsuccessful and he/she is deported. In initial stages, the therapist may simply provide a listening ear, allowing the patient to vent his/her feelings. Some such patients, after experiencing sexual or physical violence, may be very wary of authority figures. The therapist and the patient should agree on the priorities and the expected outcomes of therapy fairly earlier in their encounter so that no misapprehension remains. It is entirely possible to engage patients who have different beliefs and explanatory models as long as these views are not denigrated. 


\section{CONCLUSIONS}

Migration in itself can be a stressful experience. However, not all migrants will experience or respond to the stress in the same way. Individual responses will be influenced by a number of personal, social and cultural factors. Some of these factors can be alleviated by social support networks and cultural congruity. There is considerable evidence to suggest that some migrant groups are more at risk of developing mental disorders. Clinicians, policy makers and service providers need to be aware of specific needs that migrants may have and how these needs are met. Migrants can and do contribute positively to the new cultures and it is imperative that their mental health needs be identified in a culturally appropriate way and services delivered accordingly.

\section{Acknowledgements}

We are grateful to our reviewers, Profs. A. Cheng (Taiwan), M. Beiser (Canada) and H. Minas (Australia), for their very helpful and constructive comments. Thanks are also due to Prof. Mario Maj for inviting us and for his continuing support for the project and his comments and help in finalizing the report.

\section{References}

1. Maj M. The WPA Action Plan 2008-2011. World Psychiatry 2008;7: 129-30.

2. Maj M. The WPA Action Plan is in progress. World Psychiatry 2009; 8:65-6.

3. Bhugra D. Migration and mental health. Acta Psychiatr Scand 2004; 109:243-58.

4. Berry JW. Acculturation as varieties of adaptation. In: Padilla AM (ed). Acculturation. Boulder: Westview, 1980:9-26.

5. Berry JW. Acculturation and identity. In: Bhugra D, Bhui KS (eds). Textbook of cultural psychiatry. Cambridge: Cambridge University Press, 2007:169-78.

6. Bhugra D. Acculturation, cultural identity and mental health. In: Bhugra D, Cochrane R (eds). Psychiatry in multicultural Britain. London: Gaskell, 2001:112-36.

7. Bhugra D, Wojcik W, Gupta S. Cultural bereavement, culture shock and culture conflict: adjustments and reactions. In: Bhugra D, Gupta S (eds). Migration and mental health. Cambridge: Cambridge University Press (in press).

8. Bhugra D, Becker M. Migration, cultural bereavement and cultural identity. World Psychiatry 2005;4:18-24.

9. Boneham M. Ageing and ethnicity in Britain: the case of elderly Sikh women in a Midlands town. New Community 1989;15:447-59.

10. Livingston G, Leavey G, Kitchen G et al. Mental health of migrant elders - the Islington study. Br J Psychiatry 2001;179:361-6.

11. Lindert J, Ehrenstein S, Priebe S et al. Depression and anxiety in labor migrants and refugees - a systematic review and meta-analysis. Soc Sci Med 2009;69:246-57.

12. Laban $\mathrm{CH}$, Gernaat $\mathrm{HB}$, Komproe $\mathrm{IH}$ et al. Impact of a long asylum procedure on the prevalence of psychiatric disorders in Iraqi asylum seekers in The Netherlands. J Nerv Ment Dis 2004;192:843-51.

13. Hallas P, Hansen A, Staehr M et al. Length of stay in asylum centres and mental health in asylum seekers: a retrospective study from Denmark. BMC Public Health 2007;7:288.

14. McCrone P, Bhui KS, Craig T et al. Mental health needs, service use and costs among Somali refugees in the UK. Acta Psychiatr Scand 2005;111:351-7.

15. Laban CH, Gernaat HB, Komproe IH et al. Prevalence and predictors of health service use among Iraqi asylum seekers in The Netherlands. Soc Psychiatry Psychiatr Epidemiol 2007;42:837-44.

16. Eisenbruch $M$. The cultural bereavement interview: a new clinical and research approach with refugees. Psychiatr Clin North Am 1990;13:673-735.

17. Eisenbruch M. From post-traumatic stress disorder to cultural bereavement: diagnosis of Southeast Asian refugees. Soc Sci Med 1991;33:673-80

18. Redfield R, Linton R, Heskovits M. Memorandum on the study of acculturation. Am Anthropol 1936;38:148-52.

19. Linton R. The cultural background of personality. New York: Appleton Century Croft, 1945.

20. Boydell J, van Os J, McKenzie K et al. Incidence of schizophrenia in ethnic minorities in London: ecological study into interactions with environmnent. BMJ 2001;323:1336.

21. Krupinski J. Psychological maladaptations in ethnic concentrations in Victoria. In: Pilowsky I (ed). Cultures in collision. Adelaide: National Association for Mental Health, 1975:49-58.

22. Bhugra D. Cultural identities and cultural congruency: a new model for evaluating mental distress in immigrants. Acta Psychiatr Scand 2005;111:84-93.

23. Ödegaard O. Emigration and insanity. Acta Psychiatr Neurol Scand 1932;4(Suppl.):1-206.

24. Kirkbride J, Jones P. Epidemiological aspects of migration and mental illness. In: Bhugra D, Gupta S (eds). Migration and mental health. Cambridge: Cambridge University Press (in press).

25. Fung WLA, Bhugra D, Jones P. Ethnicity and mental health: the example of schizophrenia and related psychoses in migrant populations in the Western world. Psychiatry 2009;8:335-41.

26. Cantor-Grae E, Selten JP. Schizophrenia and migration: a metaanalysis and review. Am J Psychiatry 2005;162:12-24.

27. Cochrane R, Bal SS. Mental hospital admission rates of migrants to England - a comparison of 1971 and 1981. Soc Psychiatry Psychiatr Epidemiol 1989;24:2-12.

28. Cochrane R, Bal SS. Migration and schizophrenia: an examination of five hypotheses. Soc Psychiatry 1987;22:1981-91.

29. Hickling F, Rodgers-Johnson P. The incidence of first contact schizophrenia in Jamaica. Br J Psychiatry 1995;167:193-6.

30. Bhugra D, Hilwig M, Hossein B et al. First-contact incidence rates of schizophrenia in Trinidad and one-year follow-up. Br J Psychiatry 1996;169:587-92.

31. Mahy G, Mallett R, Leff J et al. First-contact incidence rate of schizophrenia in Barbados. Br J Psychiatry 1999;175:28-33.

32. Hanoeman M, Selten J-P, Kalm R. Incidence of schizophrenia in Surinam. Schizophr Res 2002;54:219-21.

33. Hutchinson G, Takei N, Fahy T et al. Morbid risk of schizophrenia in first degree relatives of Whites and African Caribbean patients with psychosis. Br J Psychiatry 1996;169:776-80.

34. Hutchinson G, Takei N, Bhugra D et al. Increased rates of psychosis among African Caribbeans in Britain is not due to an excess of pregnancy and birth complications. Br J Psychiatry 1997;171:145-7.

35. Mallett R, Leff J, Bhugra D et al. Social environment, ethnicity and schizophrenia: a case control study. Soc Psychiatry Psychiatr Epidemiol 2002;37:329-35.

36. Littlewood R, Lipsedge M. Some social and phenomenological characteristics of psychotic immigrants. Psychol Med 1981;11:289-92.

37. Littlewood R, Lipsedge M. Acute psychotic reactions in Caribbeanborn patients. Psychol Med 1981;11:303-18.

38. Bhugra D, Hilwig M, Mallett R et al. Factors in the onset of schizophrenia: a comparison between London and Trinidad samples. Acta Psychiatr Scand 2000;101:135-41. 
39. Stompe T, Friedmann A, Ortwein G et al. Comparison of delusions among schizophrenics in Austria and Pakistan. Psychopathology 1999;32:225-34.

40. Faris R, Denham W. Mental disorders in urban areas. New York: Hafner, 1960.

41. Parker S, Kleiner R. Mental illness in the urban Negro community. New York: Free Press, 1966.

42. Mallett R, Leff J, Bhugra D et al. Ethnicity, goal striving and schizophrenia: a case-control study of three ethnic groups in the United Kingdom. Int J Soc Psychiatry 2003;50:331-4.

43. Reininghaus U, Morgan C, Dazzan P et al. Unemployment, social isolation, achievement-expectation mismatch and psychosis: findings from the ÆSOP Study. Soc Psychiatry Psychiatr Epidemiol 2008;43:743-51.

44. Bhugra D, Ayonrinde O. Racism, racial life events and mental ill health. Advances in Psychiatric Treatment 2001;7:343-9.

45. Veling W, Selten JP, Veen $\mathrm{N}$ et al. Incidence of schizophrenia among ethnic minorities in the Netherlands: a four-year first-contact study. Schizophr Res 2006;86:189-93

46. Nazroo J. Ethnicity and mental health. London: PSI, 1997.

47. Weich S, Nazroo J, Sproston K et al. Common mental disorders and ethnicity in England: the EMPIRIC study. Psychol Med 2004;34: 1543-51.

48. Sproston K, Nazroo J (eds). Ethnic minority psychiatric illness rates in the community. London: The Stationery Office, 2002.

49. Gilbert P, Allan S. The role of defeat and entrapment (arrested flight) in depression. Psychol Med 1998;28:585-95.

50. Lipsedge M. Commentary. Advances in Psychiatric Treatment 2001; 7:222-3.

51. Jenkins J H. A state construction of affect: political ethos and mental health among Salvadoran refugees. Cult Med Psychiatry 1991;15: 139-65.

52. Holtz TH. Refugee trauma versus torture trauma: a retrospective controlled cohort study of Tibetan refugees. J Nerv Ment Dis 1998; 186:24-34.

53. Jurh WM, Kim KC. Correlates of Korean immigrants' mental health. J Nerv Ment Dis 1990;178:703-11.

54. Bhugra D. Culture and self-harm: attempted suicide in South Asians in London. Maudsley Monographs 46. London: Psychology Press, 2004.

55. Bhugra D, Desai M, Baldwin DS. Attempted suicide in West London, I. Rates across ethnic communities. Psychol Med 1999;29: 1125-30.

56. Bhugra D, Thompson N, Singh J et al. Deliberate self-harm in adolescents in West London: socio-cultural factors. Eur J Psychiatry 2004;18:91-8.

57. McKenzie K, Bhui K, Nanchahal K et al. Suicide rates in people of
South Asian origin in England and Wales: 1993-2003. Br J Psychiatry 2008;193:406-9.

58. Whitlock FA. Migration and suicide. Med J Australia 1971;2:840-8.

59. Morrell S, Taylor R, Slaytor E et al. Urban and rural suicide differentials in migrants and the Australian-born New South Wales, Australia 1985-1994. Soc Sci Med 1999;49:81-91.

60. Taylor R, Morrell S, Slaytor E et al. Suicide in urban New South Wales, Australia 1984-1994: socio-economic and migrant interactions. Soc Sci Med 1999;47:1677-86.

61. Wassanaar DR, van der Veen MBW, Pillay AL. Women in cultural transition: suicidal behaviour in South African Indian Women. Suicide Life Threat Behav 1998;28:82-93.

62. Dusovic N, Baume P, Malak A-E. Cross-cultural suicide prevention. Australia: Transcultural Mental Health Centre, 2002.

63. Lin KM, Poland RE, Nuccio I et al. A longitudinal assessment of haloperidol doses and serum concentrations in Asian and Caucasian schizophrenic patients. Am J Psychiatry 1989;146:1307-11.

64. Marcos LR, Cancro RC. Pharmacotherapy of Hispanic depressed patients: clinical observations. Am J Psychother 1982;36:505-13.

65. Strickland T, Lin K, Fu P et al. Comparison of lithium ratio between African-American and Caucasian bipolar patients. Biol Psychiatry 1995;37:325-30.

66. Westermeyer J. Somatotherapies. In: Gold JH (ed). Psychiatric care of migrants: a clinical guide. Washington: American Psychiatric Press, 1989:139-68.

67. Lee S. Side effects of chronic lithium therapy in Hong Kong Chinese: an ethnopsychiatric perspective. Cult Med Psychiatry 1993;17: 301-20.

68. Comas-Díaz L, Jacobsen FM. Ethnocultural transference and countertransference in the therapeutic dyad. Am J Orthopsychiatry 1991; 61:392-402.

69. Herbeck DM, West JC, Ruditis I et al. Variations in use of secondgeneration antipsychotic medication by race among adult psychiatric patients. Psychiatr Serv 2004;55:677-84.

70. Arranz MJ, Kapur S. Pharmacogenetics in psychiatry: are we ready for widespread clinical use? Schizophr Bull 2008;34:1130-44.

71. Ng CH, Lin K-M, Singh BS et al (eds). Ethno-psychopharmacology: advances in current practice. Cambridge: Cambridge University Press, 2008.

72. Rathod S, Kingdon D, Phiri P et al. Developing culturally sensitive cognitive-behaviour therapy for psychosis for ethnic minority patients by exploration and incorporation of service users' and health professionals' views and opinions. Report to US Department of Health Delivering Race Equality Project Group, 2009.

73. Bhugra D, Tantam D. Psychotherapy, culture and ethnicity. In: Tantam D (ed). Clinical topics in psychotherapy. London: Gaskell, 1998:241-55. 